\title{
Environmental Stress in the Gulf of Mexico and its Potential Impact on Public Health
}

${ }^{1 *}$ Singleton B, ${ }^{5}$ Turner J, ${ }^{1}$ Walter L, ${ }^{1}$ Lathan N, ${ }^{1}$ Thorpe D, ${ }^{1}$ Ogbevoen $\mathrm{P},{ }^{1}$ Daye J, ${ }^{1}$ Alcorn D, ${ }^{1}$ Wilson S, ${ }^{1}$ Semien J, ${ }^{1}$ Richard T, Johnson T, ${ }^{5} \mathrm{McCabe} \mathrm{K},{ }^{3}$ Estrada JJ, ${ }^{6}$ Galvez $\mathrm{F},{ }^{4}$ Velasco $\mathrm{C},{ }^{2,3}$ Reiss K.

${ }^{1}$ Dillard University, School of Science, Technology, Engineering and Mathematics, New Orleans, LA; ${ }^{2}$ Neurological Cancer Research, ${ }^{3}$ Stanley S. Scott Cancer Center, and ${ }^{4}$ School of Public Health, Department of Medicine, Louisiana State University Health Sciences Center, New Orleans, LA; ${ }^{5}$ University of Colorado Boulder, Department of Environmental Engineering, Boulder, CO; ${ }^{6}$ Louisiana State University, Department of Biological Sciences, Baton Rouge LA.

* Corresponding Author: Bernard Singleton, M.S., D.V.M. bsingleton@dillard.edu; 504-3446690; P.O. Box 50973, New Orleans, LA 70150 
Abstract: The Deepwater Horizon (DWH) oil spill in the Gulf of Mexico was the largest maritime oil spill in history resulting in the accumulation of genotoxic substances in the air, soil, and water. This has potential far-reaching health impacts on cleanup field workers and on the populations living in the contaminated coastal areas. We have employed portable airborne particulate matter samplers (SKC Biosampler Impinger) and a genetically engineered bacterial reporter system (umu-ChromoTest from EBPI) to determine levels of genotoxicity of air samples collected from highly contaminated areas of coastal Louisiana including Grand Isle, Port Fourchon, and Elmer's Island in the spring, summer and fall of 2011, 2012, 2013 and 2014. Air samples collected from a non-contaminated area, Sea Rim State Park, Texas, served as a control for background airborne genotoxic particles. In comparison to controls, air samples from the contaminated areas demonstrated highly significant increases in genotoxicity with the highest values registered during the month of July in 2011, 2013, and 2014, in all three locations. This seasonal trend was disrupted in 2012, when the highest genotoxicity values were detected in October, which correlated with hurricane Isaac landfall in late August of 2012, about five weeks before a routine collection of fall air samples. Our data demonstrate: (i) high levels of air genotoxicity in the monitored areas over last four years post DWH oil spill; (ii) airborne particulate genotoxicity peaks in summers and correlates with high temperatures and high humidity; and (iii) this seasonal trend was disrupted by the hurricane Isaac landfall, which further supports the concept of a continuous negative impact of the oil spill in this region.

Keywords: DWH oil spill; Gulf of Mexico; genotoxicity; air sampling; air pollutants. 
Funding sources: BS: NSF HRD-1118254; KR: P20-GM103501

Human subjects: N/A

Animal research: N/A 


\section{Introduction}

The 2010 Deepwater Horizon (DWH) oil spill in the Gulf of Mexico is the largest environmental disaster and remediation effort in the U.S. history. Approximately 800 million liters of crude oil were spilt and about 7 million liters of chemical dispersant were applied along the northern Gulf of Mexico, resulting in over 1,600 kilometers of the shoreline contaminated with weathered oil (Barron, 2012; Kleindienst et al., 2015). The closing of almost 50 million acres to fishing, hunting, and tourism, displacement of residents, and the arrival of workers recruited to participate in mitigation efforts, all contributed to the overall impact of the spill (Barron, 2012; Fisher et al., 2014). A large number of governmental and non-governmental agencies were involved in environmental relief efforts and interventions to alleviate both the environmental and economic impacts of the spill. Since the beginning of the spill, cleanup workers have been reporting acute symptoms of sickness including skin and eye irritation, respiratory problems, and headaches (D'Andrea and Reddy, 2013; King and Gibbins, 2011; Rotkin-Ellman et al., 2010). In addition, long-term health problems are also anticipated, however a direct cause and effect relationship between chronic exposure to weathered oil and health require further investigation (Diaz, 2011). Multiple chemicals and physical factors associated with the oil spill are known to cause both acute and chronic health problems. These chemicals include volatile organic compounds (VOCs): benzene, toluene, xylene, and ethyl benzene; semi-volatile compounds: polycyclic aromatic hydrocarbons (PAHs), higher molecular weight alkanes, and particulate matter (PM 2.5 and PM 10.0). In addition oil mist, carbon monoxide, gasoline and diesel engine exhausts were all present during the cleanup efforts (McCoy and Salerno, 2010).

Importantly, there was an increase of over 10-times in the concentration of the relatively low molecular weight, volatile components, including naphthalene and C-1-naphthalenes, and in higher molecular weight analytes between September 2010 and October 2012 in heavily oiled 
marsh in Louisiana (Turner et al., 2014). Although these volatile components are well known to trigger both immune responses, and cause DNA damage in affected organisms including humans (Alpha et al., 2015; Tagiyeva and Sheikh, 2014; Wang et al., 2013; Wang et al., 2014), air sampling and the evaluation of airborne particulates have not been used in the assessment of health risks associated with oil spills. Our research team collected and analyzed airborne particulate matter (PM) samples from three areas of coastal Louisiana, which according to the U.S. Environmental Protection Agency (EPA) demonstrated heavy contamination with the natural crude oil post DWH oil spill. These include Grand Isle, Port Fourchon, and Elmer's Island. The PM samples were collected in the spring, summer and fall of 2011, 2012, 2013 and 2014. Our data demonstrate: (i) persistent air genotoxicity in the monitored areas of coastal Louisiana over the last four years; (ii) air genotoxicity peaks in the summers, which correlated with high temperatures and high air humidity; and (iii) this seasonal trend was disrupted by the hurricane Isaac landfall, which caused a further increase of air genotoxicity in the fall of 2012. In conclusion, our data indicate a continuous negative health impact of DWH oil spill, which persists in the monitored regions of the Gulf, and supports the need for a continuous monitoring of air quality in this region. 


\section{Materials and methods}

2.1 Air sample collection and storage: BioSampler Impinger (SKC, Inc.) with sonic flow sample pumps were used according to manufacturer recommendations. Briefly, particulate matter (PM) recovered from size-segregated air samples were collected from oil-impacted beaches at Port Fourchon, Elmer's Island, and Grand Isle, Louisiana. These air samples were collected during 8-hour sampling campaigns, which occurred on consecutive days over weekends in March, July, and October of 2011, 2012, 2013 and 2014. Airborne PM samples collected from a non-contaminated area (Sea Rim State Park, TX) were used as controls. The samples were than stored at $-80{ }^{\circ} \mathrm{C}$ until further analyses. The selection of oil impacted sites was made by using air quality data gathered through the U.S. Environmental Protection Agency (EPA) in response to the DWH oil spill to identify the most heavily impacted regions in the Gulf (2011 United States Environmental Protection Agency). Permits were aquired from the Louisiana State Park Service to collect samples in Grand Isle State Park, one of the most adversely affected coastal shorelines of Louisiana.

2.2 Genotoxicity of Air Samples: A standard bacterial reporter assay (umu-ChromoTest from EBPI) was used to determine the genotoxicity of the collected PM samples. In this assay, DNA damage induces activity of the reporter gene, umuC, as a part of genotoxic response. In this system, the umuC gene is fused to lacZ, thus its activation results in the production of Bgalactosidase, measured using a standard colorimetric reaction and UV-VIS plate reader (FilterMax F5, Molecular Devices). The results are expressed as Induction Ratios, which were calculated using the formula recommended by the manufacturer in which the positive control is the response to the known genotoxic compound [4-nitroquinoline 1-oxide (4NQO)], and the negative control is the response to the elution buffer. Accordingly, the Induction Ratio of 1.5 was determined as the baseline for the genotoxicity. In particular, a series of dilutions of the air 
samples were tested to select a dilution, which is not cytotoxic to bacteria, and still triggers high genotoxic response.

2.3 Meteorological Data: Meteorological data were logged (ACU>RITE Professional Weather Center-5-in-1 wireless sensor) at the collection sites during PM sampling campaigns. The data include: temperature $(F)$, humidity $(\%)$, wind direction, wind speed $(\mathrm{mph})$, heat index $(\mathrm{F})$, dew point $(F)$, and wind chill $(F)$.

2.4 Statistical analysis: Statistical evaluation was based on one-way ANOVA with Satterthwaite correction for unequal variances, followed with multiple comparisons of mean Induction Ratios with $p$-values adjusted via simulation to keep an overall alpha of $\geq 0.05$. 


\section{Results}

Large-scale oil spills increase the overall concentration of toxic chemicals in affected environments. Some of these substances, such as volatile organic compounds (VOCs) and semi-volatile polycyclic aromatic hydrocarbons (PAHs), can be released from water and sediments affecting the quality of air in areas heavily contaminated with the natural crude oil. To address the potential health risk associated with chronic exposure to natural crude oil, we collected air samples from coastal areas polluted by the 2010 DWH oil spill in the Gulf of Mexico. Figure 1 shows the locations of three collection sites, which are superimposed on the map of relative oiling of the Louisiana coastline as of January 23, 2011 (Jan 232011 Environmental Response Management Application® $(\mathrm{ERMA}))$ derived as part of the Shoreline Cleanup Assessment Technique (SCAT) Program. The samples were collected from Grand Isle (A), Port Fourchon (B), and Elmers' Island (C) in spring, summer and fall of 2011, 2012, 2013 and 2014 using portable PM samplers (SKC Biosampler Impinger). The collected samples were stored in $-80^{\circ} \mathrm{C}$, and were subsequently tested for the ability to induce a genotoxic response in genetically engineered bacterial reporter system (umu-ChromoTest from EBPI). PM samples collected from a non-contaminated area (Sea Rim State Park, TX) served as a control for background genotoxicity. The results in Fig. 2 demonstrate that samples collected from Grand Isle in March, July and October of 2011 demonstrated 443\%, 570\%, and $315 \%$ increases in genotoxic response (expressed as Induction Ratio) in comparison to the corresponding control samples. Significant increases in genotoxicity were also detected in samples from Elmer's Island and Port Fourchon, LA. Genotoxicity analysis of samples from Elmer's Island in 2011 demonstrated a 356\% increase in March, 440\% increase in July, and $264 \%$ increase in October. Analysis of samples collected at Port Fourchon demonstrated a 198\% increase in March; 397\% increase in July; and 223\% increase in October (all statistically significant). 
Additionally, we also observed significantly higher genotoxicity values in July 2011 in comparison to March and October of the same year in all three locations. The results in Fig. 3A demonstrate that combined genotoxicity levels (from all three Louisiana locations) were $24 \%$ higher in July in comparison to March $(\mathrm{p}=0.048)$; and $37 \%$ higher in comparison to October $(p=0.001)$. This seasonal trend of high summertime genotoxicity was also observed in 2013 and in 2014 (Fig. 3A). In contrast, this trend was not observed in 2012, when the highest genotoxicity values were observed in October. July 2012 samples exhibited significant increase in genotoxicity, both in comparison to controls (Fig. 2, last column) and in comparison to experimental samples collected in March of the same year (Fig. 3A). However, October samples from 2012 were collected 2 weeks after Hurricane Isaac made a landfall in late August of 2012. It is probable that this extreme weather condition increased the content of genotoxic substances in the airborne PM samples collected from the coastal area, which is still heavily loaded with natural crude oil and dispersants, and could be responsible for this effect.

Another key finding of this study is the persistence of air genotoxicity observed in all three locations over last four years (Fig. 2). In Grand Isle for example, March samples demonstrate average genotoxicity induction rates of $4.6+/-0.14 ; 3.7+/-0.03 ; 3.6+/-0.1$, and 3.1+/-0.05 in 2011, 2012, 2013 and 2014, respectively. In July, genotoxic values in this area were $5.7+/-0.9 ; 4.54+/-0.05 ; 4.24+/-0.1 ;$ and $4.4+/-0.35$ in 2011, 2012, 2013 and 2014, respectively. In October, genotoxicity values were 3.74+/-0.03; 5.34+/-0.1; 3.6+/-0.08; and 3.2+/-0.16 in 2011, 2012, 2013 and 2014, respectively. Results illustrated in Fig. 3B demonstrate a direct comparison of air genotoxicity between air samples collected in 2011 and 2014. In this comparison average data from all three locations have been combined together and grouped as average induction ratios for March, July and October 2011, and were compared with induction ratios obtained from March, July and October 2014. This direct comparison demonstrated only marginal (not significant) changes in PM genotoxicity between 
2011 and 2014. These findings indicate the persistent presence of genotoxic PM in the air from these selected coastal areas of southern Louisiana.

Meteorological data presented in Figure 4 were utilized to compare genotoxicity of the air samples with weather parameters registered during sampling campaigns. These weather parameters include temperature $\left({ }^{\circ} \mathrm{F}\right)$, humidity $(\%)$, wind direction, wind speed $(\mathrm{mph})$, heat index $\left({ }^{\circ} \mathrm{F}\right)$, dew point $\left({ }^{\circ} \mathrm{F}\right)$ and wind chill $\left({ }^{\circ} \mathrm{F}\right)$. These data were utilized to evaluate seasonal trend of maximum genotoxicity observed in July of 2011, 2013, and 2014 (Fig. 3A), and to address possible correlation between genotoxicity and the extreme meteorological conditions associated with hurricane Isaac (Fig. 3A, histogram corresponding to year 2012). The results in Fig. 5A demonstrate a highly significant correlation of elevated genotoxicity (Induction Ratio) with temperature. In this calculation, all temperature records, expressed in Fahrenheit $\left({ }^{\circ} \mathrm{F}\right)$, have been divided in to four arbitrary temperature brackets: 30-45, 46-60, 61-75 and over 75 ${ }^{\circ} \mathrm{F}$. Statistically significant increments of genotoxicity induction rates were detected between almost all temperature brackets when lower temperature brackets were compared to higher temperature brackets (five comparisons). One exception to this trend was observed when 46$60{ }^{\circ} \mathrm{F}$ temperature bracket was compared to the $61-75^{\circ} \mathrm{F}$ temperature bracket.

We also observed elevated correlation between genotoxicity and humidity (Fig. 5B). In this comparison statistical significance was reached only when $50-59 \%$ humidity bracket was compared either with $60-69 \%$ humidity brackets $(p=0.0001)$, or with $70-79 \%$ humidity bracket ( $p=0.0001$ ). Of note, increases in humidity from $60-69 \%$ to $70-79 \%$ did not significantly affect genotoxicity induction rates. These analyses demonstrated positive correlations between DWH oil spill related PM genotoxicity, with temperature and humidity, which were evaluated here using temperature and humidity groups relevant to the daily and seasonal changes in this region. These correlations between genotoxicity and meteorological data may also explain why 
genotoxicity peaks most commonly in summers, when both temperature and humidity are the highest.

In conclusion, these findings indicate that potential health risks associated with persistent airborne PM genotoxicity exist in locations along coastal Louisiana heavily oiled by the DWH oil spill. As such, this research advocates for continued monitoring of air quality in this region. 


\section{Discussion}

The results of this study demonstrate elevated levels of airborne PM genotoxicity in the monitored areas of coastal Louisiana over the first four years post DWH oil spill. In particular, air genotoxicity peaks during summers, which correlates with high temperatures and high humidity levels. Analyses also indicate that this seasonal trend was disrupted by the hurricane Isaac landfall in September 2012, which further supports the conceptual model of a continuous release of the oil likely generated from the oil deposits that remain in the Gulf post DWH oil spill.

In terms of a direct environmental impact, research has provided new insights into oil spills that occur at unprecedented depths, release enormous amounts of oil that for the most part is retained at deep sea levels, emulsifies and disperses due to deep pressures, and affects marine ecosystems for long periods of time (Kleindienst et al., 2015; Lubchenco et al., 2012). These deep water spills behave differently from the more common contamination caused by broken pipelines and ruptured tankers; wherein oil floats to the surface, and can be dispersed chemically or by natural weathering. The use of unprecedented amounts of dispersants at the origin of the DWH oil spill is controversial because the natural behavior of

deep oil spills is to remain deep below the surface, however, dispersants have already disrupted this natural process (Kleindienst et al., 2015; Lubchenco et al., 2012). Recent studies also indicate that the oil from DWH spill continues to resurface (Warnock et al., 2015). These oil deposits are suspected to be realsed continously to the surface due to chemical modifications (weathering) of the oil/dispersant complexes and/or by high pressure-induced emulsification of the oil (Gong et al., 2014; Lubchenco et al., 2012). Our data illustrate that both seasonal (temperature and humidity) and extreme (hurricane landfall) weather conditions have the potential to continously increase air genotoxicity near the oil spill impacted shorelines. 
As a part of the global health response, the National Institute for Environmental Health Sciences (NIEHS) has initiated large-scale epidemiological study to investigate health of the cleanup workers (GuLF Study) (Sandler et al., 2012). Briefly, it involves a cohort of approximately 55,000 workers who are administered a questionnaire to obtain information on the subjects' overall health status and the cleanup jobs in which they were engaged. In addition, two sub cohorts: Active Follow-up Sub-cohort and Biomedical Surveillance Subcohort have been established for blood, urine, hair, fingernails, household dust collection; and for more detailed neurological and physiological assessment. These efforts have been employed to determine the overall health status and possible health effects associated with the persistence of contamination in these populations, and will be useful for evaluation in conjugation with ongoing studies on the Gulf environment.

Multiple chemicals associated with the oil spill can potentially cause both acute and chronic health problems. These also include volatile organic compounds (VOCs) such as benzene, toluene, xylene, and ethyl benzene, and semi-volatile compounds such as polycyclic aromatic hydrocarbons (PAHs). Although chronic effects of low doses of these substances on human health are not well defined, several PAHs are classified as potent carcinogens, which form covalent DNA adducts and cause oxidative DNA damage (Ji et al., 2010; Liu et al., 2010; Seike et al., 2003; Xue and Warshawsky, 2005). In respect to cancer risk, these PAH-induced primary DNA lesions may result in the accumulation of random mutations when cellular mechanisms responsible for DNA repair fidelity are compromised by inherited mutations of genes involved in DNA repair (Shields, 1993), excessive DNA damage, or by oncogenic viruses (Morales-Sanchez and Fuentes-Panana, 2014; White et al., 2005; Wilk et al., 2013). Further epidemiological studies are required to verify if indeed PM-induced DNA damage can contribute to the increased incidence of cancer especially in individuals whom are already predisposed to cancer by inherited mutations or oncogenic viruses. 


\section{Conclusions}

The impact of the DWH oil spill extended beyond the damage of natural resources and called for comprehensive remediation, a conclusion that has prompted revision of current approaches that are mostly focused on calculating the damage and replacing value of individual resources. Possible health effects of the oil spill, both acute and chronic, are often neglected in these calculations, especially long-term health effects, which are still difficult to estimate. In this respect our current study provides a simple and low-cost approach of monitoring airborne PM genotoxicity as a possible surrogate marker in the assessment of health risks associated with oil spills. 


\section{Acknowledgements}

This research project was supported by: NSF HRD-1118254 awarded to BS, and P20GM103501 awarded to KR.

We would like to thank the following Dillard University student researchers: Chardai Grays C, Jasmine Scott, Brianna Ryan, Ashley Pinkins, De'Jhon Bryant, and James Watson for their contribution in collecting and processing of the environmental samples. In addition, we would like to acknowledge Drs. Mark Hernandez and Alina Handorean from the University of Colorado Boulder for their support in training and mentoring of our student researchers. 


\section{Figure legends}

Figure 1: Relative oiling of northern Gulf of Mexico coastline based on Shoreline Cleanup and Assessment Technique (SCAT) data as of Jan 23, 2011. Different degrees of contamination with natural crude oil are indicated: heavy contamination (Red and Orange), intermediate contamination (Yellow and Green), and light contamination (Blue). Superimposed letters A, B and C correspond to Grand Isle, Port Fourchon and Elmer's Island, Louisiana, respectively, and indicate sites of the collection of air samples in spring, summer and fall of 2011, 2012, 2013 and 2014.

Figure 2: Post DWH air samples were collected with SKC Biosampler Impinger from highly contaminated costal areas of Grand Isle, Elmer's Island and Port Fourchon, Louisiana (indicated as A, B and C in Fig. 1) in spring, summer and fall of 2011, 2012, 2013, and 2014. The air samples have been also collected from the control area (Sea Rim State Park, TX), which was not exposed to the DWH oil spill. Overall genotixicity of the collected air samples was evaluated using genetically engineered bacterial reporter, umu-ChromoTest from EBPI. In this assay, DNA damage activates the reporter gene, umuC, as a part of genotoxic response. In this system, the umuC gene is fused to lacZ, thus its activation results in the production of Bgalactosidase. The samples were processed according to the manufacturer recommendation (umu-ChromoTest, EBPI) and B-galactosidase activity was evaluated using UV-VIS Spectroscopy plate reader, OD600. The results are expressed as Induction Ratios and were calculated using the formula recommended by the manufacturer in which the positive control is the response to the known genotoxic compound [4-nitroquinoline 1-oxide (4NQO)]), and negative control is the response to the elution buffer. Accordingly, the Induction Ratio of 1.5 
and above (indicated by red line) is considered genotoxic. Data represent average values from 3 experiments with standard deviation $(n=3)$.

Figure 3: The data from Figure 2 have been grouped and analyzed to emphasize seasonal changes (Panel A) and persistence (Panel B) of air genmotoxicity using all air samples collected. The data (Induction Ratios) from all three Louisiana locations have been pulled together and grouped according to the month and year of the collection. Data represent average values with standard deviation. Statistically significant differences $(p \leq 0.05)$ between groups are indicated above corresponding bars in Panel $A$, and $p$ values for Panel $B$ are presented in the table next to the bar graph.

Figure 4: Weather parameters including temperature $(F)$, humidity $(\%)$ wind direction, wind speed (mph), heat index $(F)$, dew point $(F)$ and wind chill $(F)$ have been collected using Weather monitoring equipment (ACU>RITE Professional Weather Center-5-in-1 wireless sensor). These weather parameters were registered at the time of the collection of air samples from Grand Isle, Port Fourchon and Elmer's Island, Louisiana, in spring, summer and fall of 2011, 2012, 2013 and 2014.

Figure 5: Relative humidity of the air and high temperature contribute to the increased air genotoxicity. All genotoxicty data from Fig. 3 have been additionally grouped to determine if seasonal changes in air genotoxicity (Induction Ratio) correlate with the existing weather parameters registered at the time of air sample collection (Fig. 2). The results depicted in Panel A demonstrate how the Induction Ratio data segregate between arbitrary selected ranges of the temperature (30-45 F; 46-60 F; 61-75 F; and over $75 \mathrm{~F})$. The data demonstrate statistically significant increases in the Induction Ratio with the increasing temperature 
between all four groups. The results in Panel B demonstrate a similar correlation, which have been calculated between the Induction Ratio data and humidity data arbitrary divided in to three groups (50-59\%; $60-69 \%$ and $70-79 \%)$. The results demonstrate statistically significant increases in the Induction Ratio when the lowest humidity (50-59\%) was compared either to intermediate humidity $(60-69 \%)$ or high humidity $(70-79 \%)$. We did not observed statistically significant changes in the Induction Ratio when $60-69 \%$ and $70-79 \%$ groups were compared. Statistical evaluation was based on one-way ANOVA with Satterthwaite correction for unequal variances, followed with multiple comparisons of mean Induction Ratios with p-values adjusted via simulation to keep an overall alpha $=0.05$. 


\section{References}

EPA Response to the BP Spill in the Gulf pf Mexico. Air data from the Gulf coastline http://www.epa.gov/bpspill, 2011 United States Environmental Protection Agency.

ERMA Deepwater Gulf Response http://gomex.erma.noaa.gov/erma.html - /x=90.35069\&y=28.85664\&z=8\&layers $=6770+15879+19897+19872+17176$, Jan 232011 Environmental Response Management Application® (ERMA), pp. 23-Jan-11 Houma SCAT Maximum Oiling.

Alpha, C. J., et al., 2015. Mycofumigation by the volatile organic compound-producing Fungus Muscodor albus induces bacterial cell death through DNA damage. Appl Environ Microbiol. 81, 1147-56.

Barron, M. G., 2012. Ecological impacts of the deepwater horizon oil spill: implications for immunotoxicity. Toxicol Pathol. 40, 315-20.

D'Andrea, M. A., Reddy, G. K., 2013. Health consequences among subjects involved in Gulf oil spill clean-up activities. Am J Med. 126, 966-74.

Diaz, J. H., 2011. The legacy of the Gulf oil spill: analyzing acute public health effects and predicting chronic ones in Louisiana. Am J Disaster Med. 6, 5-22.

Fisher, C. R., et al., 2014. Footprint of Deepwater Horizon blowout impact to deep-water coral communities. Proc Natl Acad Sci U S A. 111, 11744-9.

Gong, Y., et al., 2014. A review of oil, dispersed oil and sediment interactions in the aquatic environment: influence on the fate, transport and remediation of oil spills. Mar Pollut Bull. 79, 16-33.

$\mathrm{Ji}$, G., et al., 2010. Interactions between exposure to environmental polycyclic aromatic hydrocarbons and DNA repair gene polymorphisms on bulky DNA adducts in human sperm. PLoS One. 5.

King, B., Gibbins, J., Health Hazard Evaluation of Deepwater Horizon Response Workers. In: C. f. D. C. a. P. US Department of Health and Human Services, National Institute for Occupational Safety and Health, Health Hazard Evaluation Program, (Ed.), 2011.

Kleindienst, S., et al., 2015. Using dispersants after oil spills: impacts on the composition and activity of microbial communities. Nat Rev Microbiol. 13, 388-96.

Liu, H. H., et al., 2010. Oxidative damage in foundry workers occupationally co-exposed to PAHs and metals. Int J Hyg Environ Health. 213, 93-8.

Lubchenco, J., et al., 2012. Science in support of the Deepwater Horizon response. Proc Natl Acad Sci U S A. 109, 20212-21.

McCoy, M., Salerno, J., ASSESSING THE EFFECTS OF THE GULF OF MEXICO OIL SPILL ON HUMAN HEALTH. http://www.diversitypreparedness.org/browseresources/resources/IOM Gulf Spill, 2010, pp. This publication summarizes the background, presentations, discussions, and public comments that occurred during the IOM workshop on June 22-23, 2010, in New Orleans, LA, assessing the human health effects of the Gulf of Mexico oil spill.

Morales-Sanchez, A., Fuentes-Panana, E. M., 2014. Human viruses and cancer. Viruses. 6, 4047-79.

Rotkin-Ellman, M., et al., 2010. Gulf oil spill air quality monitoring: lessons learned to improve emergency response. Environ Sci Technol. 44, 8365-6.

Sandler, D., et al., Gulf Long-Term Follow-Up Study. Vol. Version 14.0 (09/23/12). National Institute of Environmental Health Sciences (NIEHS), 2012, pp. 1-184. 
Seike, K., et al., 2003. Oxidative DNA damage induced by benz[a]anthracene metabolites via redox cycles of quinone and unique non-quinone. Chem Res Toxicol. 16, 1470-6.

Shields, P. G., 1993. Inherited factors and environmental exposures in cancer risk. J Occup Med. 35, 34-41.

Tagiyeva, N., Sheikh, A., 2014. Domestic exposure to volatile organic compounds in relation to asthma and allergy in children and adults. Expert Rev Clin Immunol. 10, 1611-39.

Turner, R. E., et al., 2014. Changes in the concentration and relative abundance of alkanes and PAHs from the Deepwater Horizon oiling of coastal marshes. Marine Pollution Bulletin. 86, 291-297.

Wang, F., et al., 2013. Oxidative damage and genotoxic effect in mice caused by sub-chronic exposure to low-dose volatile organic compounds. Inhal Toxicol. 25, 235-42.

Wang, F., et al., 2014. Effects of subchronic exposure to low-dose volatile organic compounds on lung inflammation in mice. Environ Toxicol. 29, 1089-97.

Warnock, A. M., et al., 2015. Marine Tar Residues: a Review. Water Air Soil Pollut. 226, 68.

White, M. K., et al., 2005. Human polyomaviruses and brain tumors. Brain Res Brain Res Rev. 50, 69-85.

Wilk, A., et al., 2013. Polycyclic aromatic hydrocarbons - induced ROS accumulation enhances mutagenic potential of T-antigen from human polyomavirus JC. J Cell Physiol.

Xue, W., Warshawsky, D., 2005. Metabolic activation of polycyclic and heterocyclic aromatic hydrocarbons and DNA damage: a review. Toxicol Appl Pharmacol. 206, 73-93. 


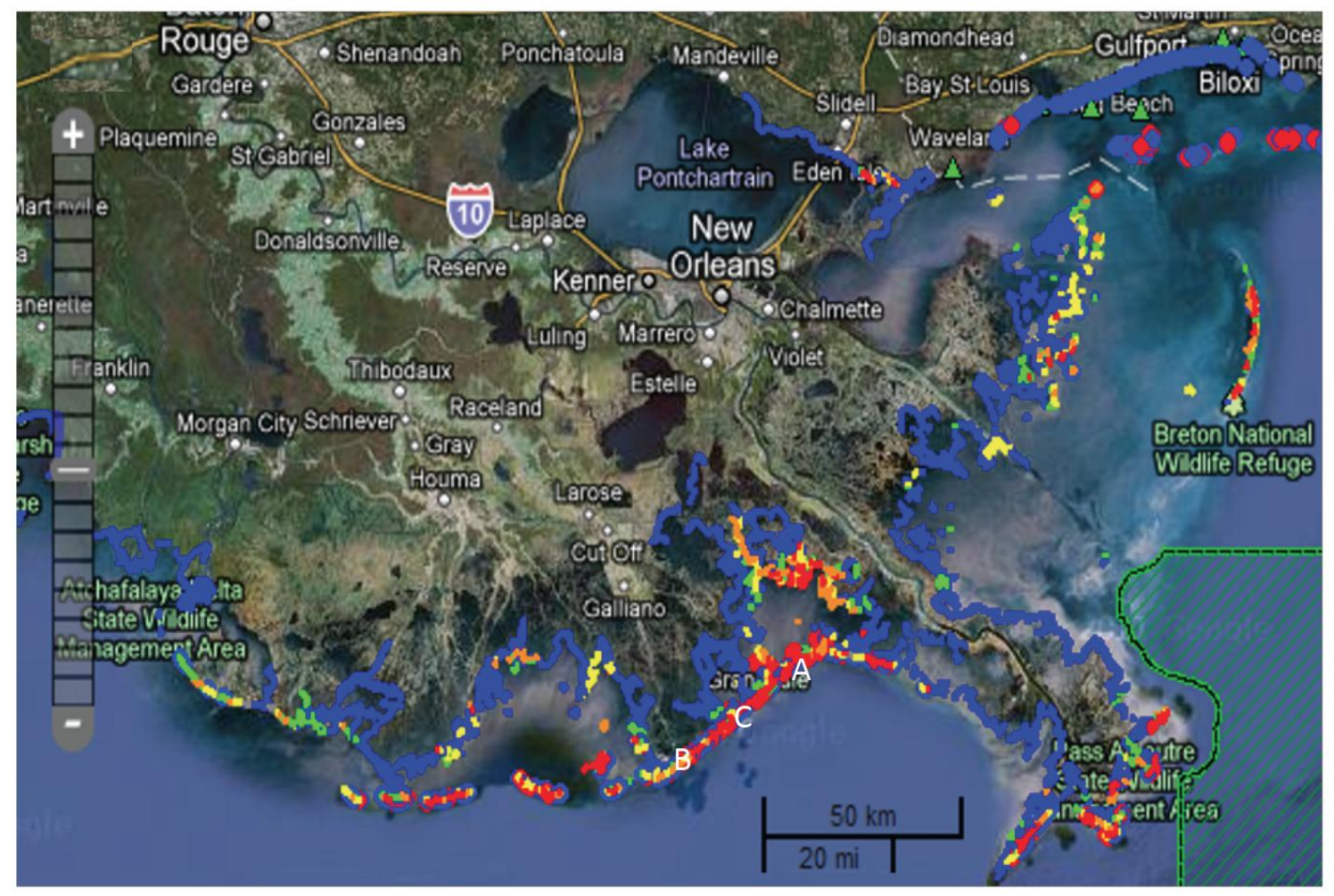

Oiled Louisiana Coastline as of Jan 23, 2011

Oiled: non-Oiled Red, Yellow, Green, Blue Respectively 
2011
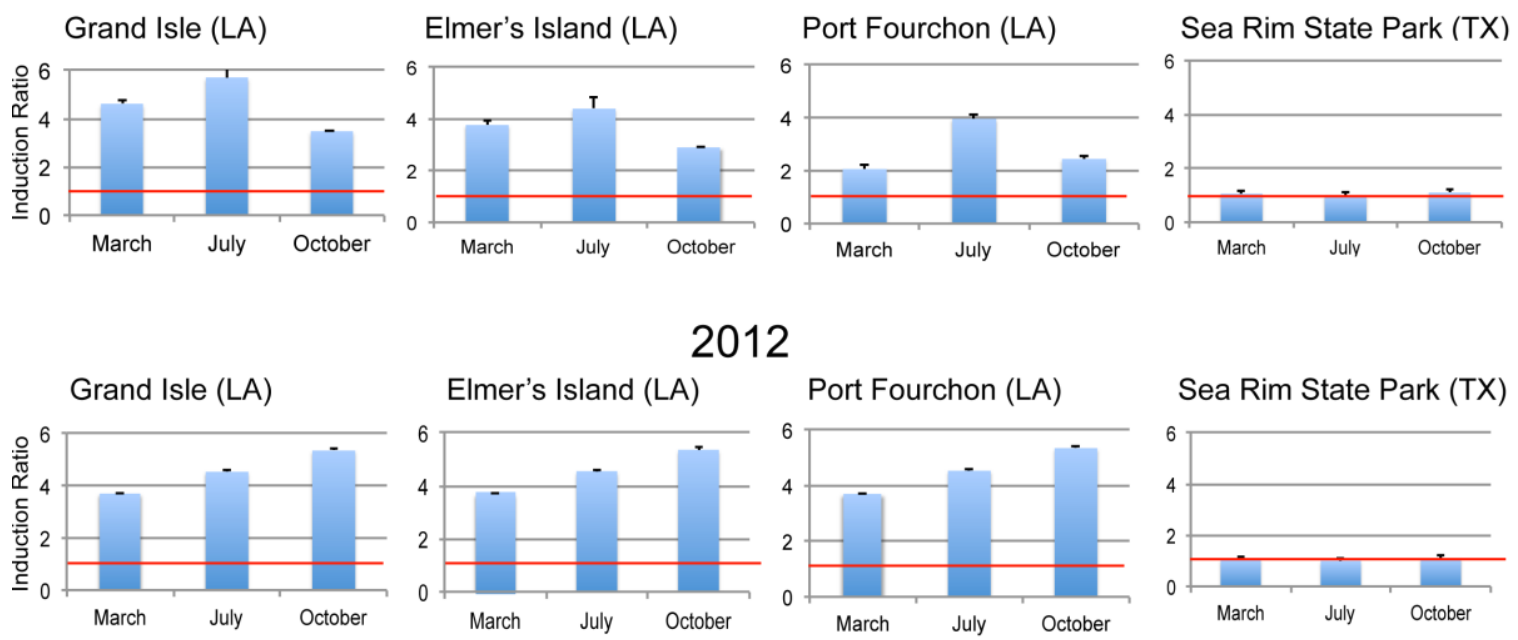

\section{3}
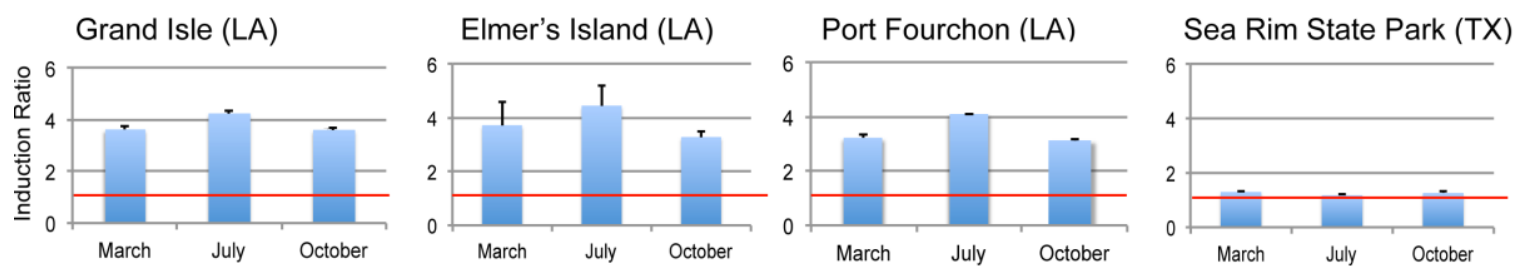

\section{4}
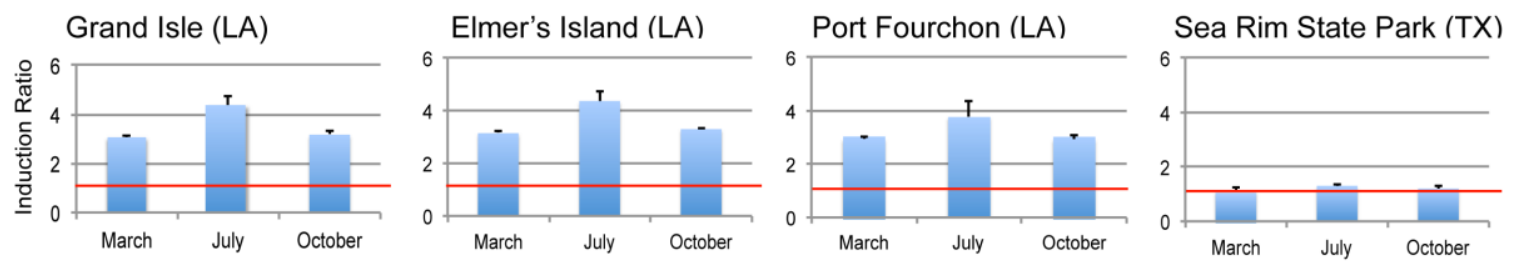


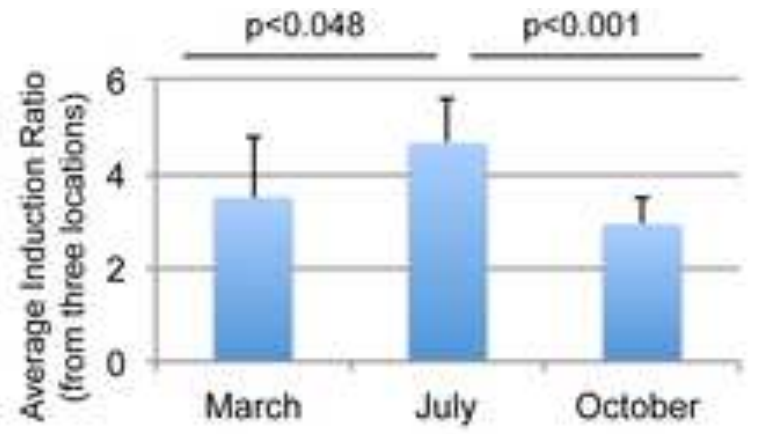

2012

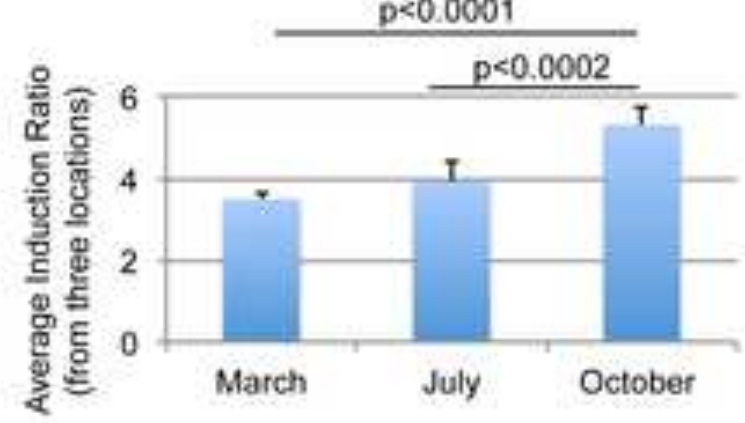

2013

2014

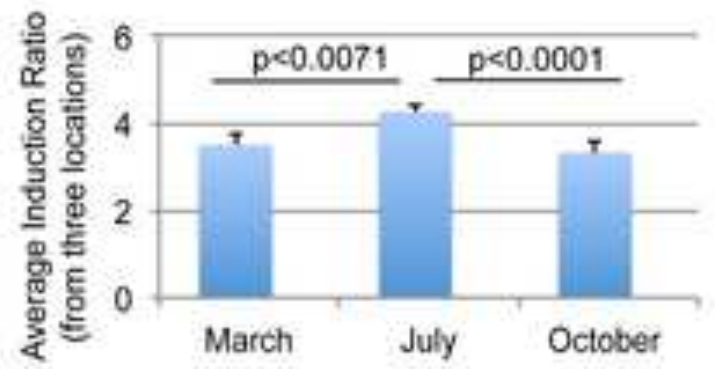

B
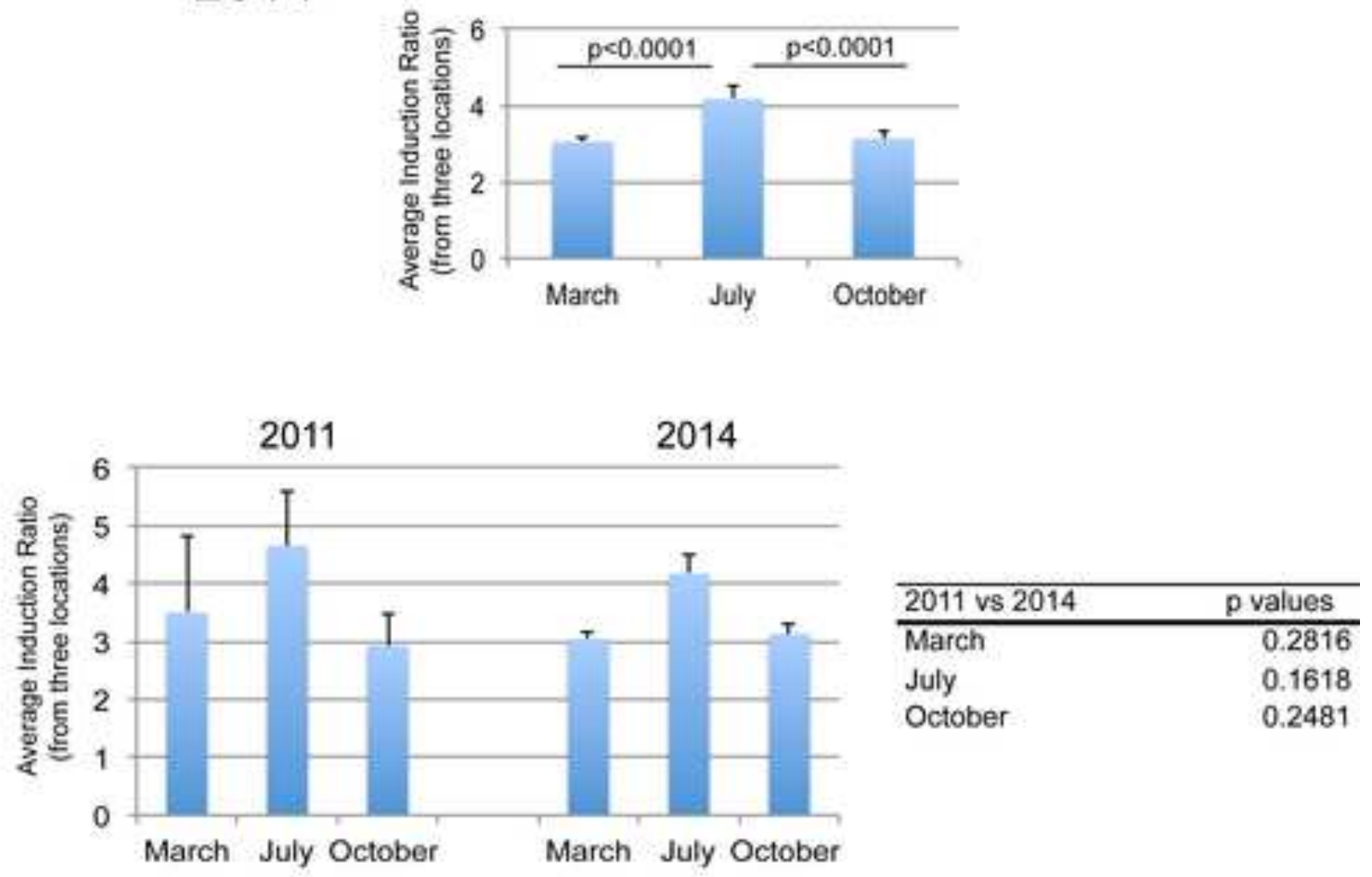
Weather Monitoring equipment

\begin{tabular}{|c|c|c|c|c|c|c|c|}
\hline $\begin{array}{l}\text { Season } \\
2011\end{array}$ & Temp. F & $\begin{array}{c}\text { Humidity } \\
\%\end{array}$ & $\begin{array}{l}\text { Wind } \\
\text { Direction }\end{array}$ & $\begin{array}{l}\text { Wind } \\
\text { Speed } \\
\text { mph }\end{array}$ & $\begin{array}{l}\text { Heat } \\
\text { Index } \\
\text { F }\end{array}$ & $\begin{array}{l}\text { Dew } \\
\text { Point } \\
\text { F }\end{array}$ & $\begin{array}{l}\text { Wind } \\
\text { Chill } \\
\text { F }\end{array}$ \\
\hline March & $50-57$ & $54-56$ & S-S/E & $6-10$ & $50-56$ & $43-48$ & $48-55$ \\
\hline July & $90-93$ & $65-67$ & S/E & $7-10$ & $91-98$ & $63-70$ & $86-88$ \\
\hline October & $64-68$ & $52-54$ & $S$ & $5-7$ & $62-67$ & $54-57$ & $53-59$ \\
\hline \multicolumn{8}{|l|}{2012} \\
\hline March & $55-58$ & $55-57$ & S/E & $5-11$ & $54-56$ & $44-46$ & $50-54$ \\
\hline July & $86-94$ & $67-71$ & $S$ & $5-10$ & $88-94$ & $63-72$ & $83-88$ \\
\hline October & $64-68$ & $71-76$ & S/E & $4-11$ & $63-65$ & $55-58$ & $57-60$ \\
\hline \multicolumn{8}{|l|}{2013} \\
\hline March & $45-47$ & $52-58$ & S/E & $5-8$ & $45-48$ & $43-47$ & $42-44$ \\
\hline July & $88-94$ & $65-75$ & $S$ & $5-9$ & $90-95$ & $72-78$ & $80-86$ \\
\hline October & $60-67$ & $74-77$ & S/E & $4-11$ & $61-68$ & $59-65$ & $58-64$ \\
\hline \multicolumn{8}{|l|}{2014} \\
\hline March & $35-38$ & $53-56$ & S- S/E & $5-8$ & $34-38$ & $52-54$ & $34-38$ \\
\hline July & $85-92$ & $65-67$ & S/E & $5-12$ & $87-93$ & $71-74$ & $87-89$ \\
\hline October & $63-67$ & $50-55$ & S/E & $5-10$ & $64-66$ & $62-65$ & $62-69$ \\
\hline
\end{tabular}

1.Table: Weather Conditions 

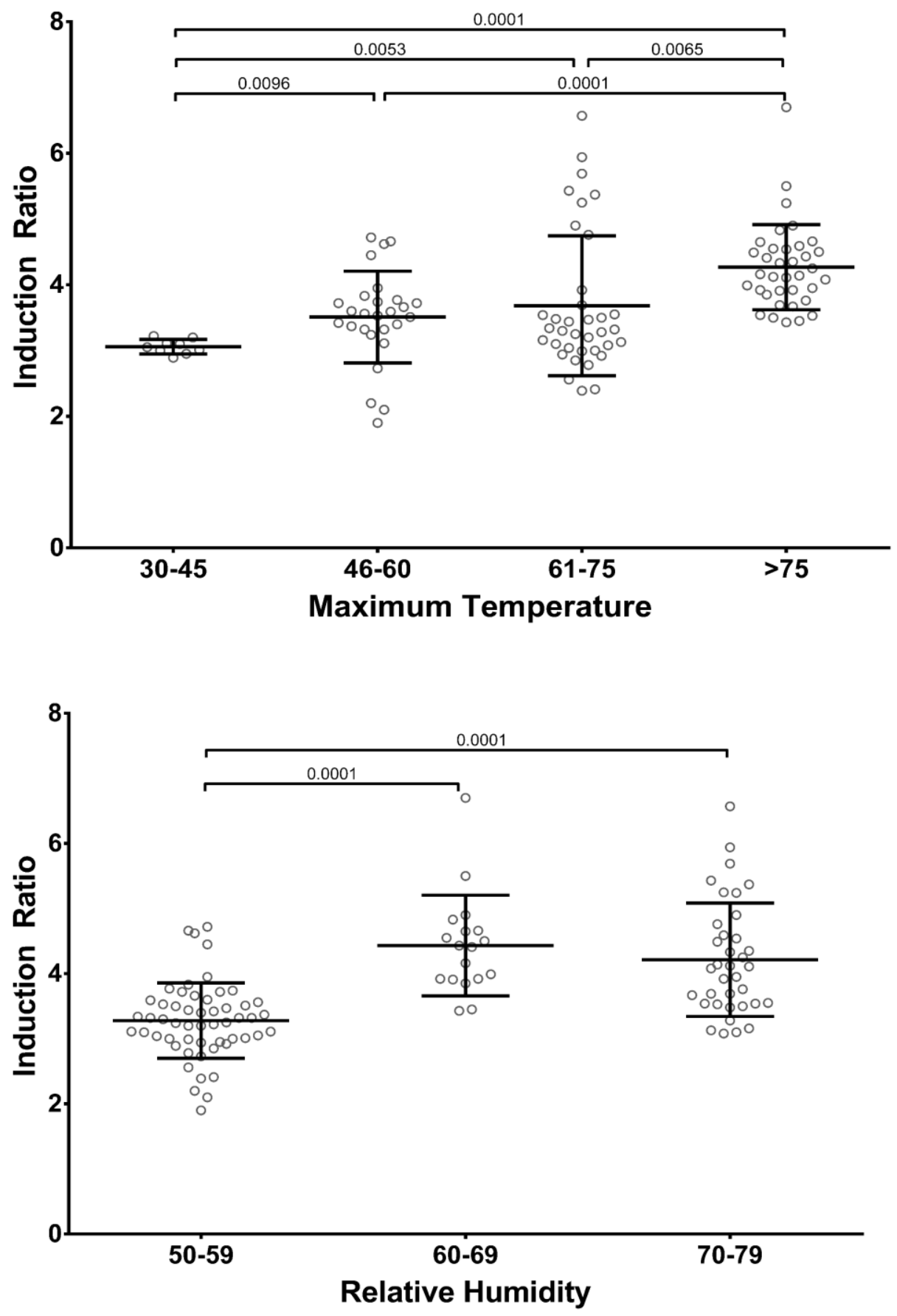